\title{
Cytogenetic analysis of global populations of Mugil cephalus (striped mullet) by different staining techniques and fluorescent in situ hybridization
}

\author{
ANNA RITA ROSSI, DONATELLA CROSETTI†, EKATERINA GORNUNG \& LUCIANA \\ SOLA* \\ Department of Animal and Human Biology, University of Rome 1, Via A. Borelli 50, 00161 Rome and †/CRAM, \\ Central Institute for Marine Research, Via L. Respighi 5, 00197 Rome, Italy
}

\begin{abstract}
The present paper reports the results of cytogenetic analysis carried out on several scattered populations of the striped mullet, Mugil cephalus, the most widespead among mugilid species. The karyotype was investigated through Ag-staining, C-banding, fluorochrome-staining (chromomycin $\mathrm{A}_{3} / \mathrm{DAPI}$ ) and fluorescent in situ hybridization with rDNA genes. All populations showed the same chromosome number and morphology and no changes were detected in heterochromatin and NORs. Therefore, neither population- nor sex-specific marker chromosomes were identified. In some of the specimens, NOR size heteromorphism was detected. Results are discussed with respect to karyotype and ribosomal cistrons organization and to cytotaxonomic implications.
\end{abstract}

Keywords: cytotaxonomy, FISH, heterochromatin, karyotype, NOR.

\section{Introduction}

The striped mullet, Mugil cephalus, is the most widespread among mugilid species, and inhabits the tropical and subtropical seas of the world. Both the worldwide distribution, the range discontinuity (Thomson, 1963) and the coastally-dependent life history have raised questions on the conspecificity of local populations of this species. It is indeed possible that, because of limited gene-flow, some populations have genetically diverged but the conservative morphology of mullets prevents the detection of such differentiation.

This karyological study is part of a survey dealing with the geographical variation and genetic differentiation of $M$. cephalus, applying different approaches on samples collected worldwide. Results from mitochondrial DNA (mtDNA) (Crosetti et al., 1994), gene-enzyme (Rossi et al., 1995) and morphometric (Corti \& Crosetti, 1995) analyses have already been published. In these papers, the systematics and the biogeography of $M$. cephalus are discussed.

\footnotetext{
*Correspondence.
}

Although the karyotype of $M$. cephalus is already known (Table 1), there are no data from differential staining techniques, except for observations on nucleolar organizer regions (NORs) by Amemiya \& Gold (1986). Moreover, previous studies cover only few localities from the wide species range and specimens from more than one collecting site have never been observed in the same laboratory. This paper reports a cytogenetic characterization of six mullet samples from worldwide-distributed locales by means of several staining techniques and fluorescent in situ hybridization (FISH).

\section{Materials and methods}

The collection of mullet samples within the whole research programme was carried out during field trips at a total of 13 localities worldwide (Crosetti et al., 1994; Rossi et al., 1995). The cytogenetic preparations were performed for all populations but good results were obtained mainly from specimens returned alive to the laboratory and processed there. Thus, this paper reports cytogenetic observations (Table 2) on 25 specimens from six collecting sites: Fiumicino (F: Italy, West Coast, Mediterranean 
Table 1 Cytogenetic studies on Mugil species

\begin{tabular}{|c|c|c|c|c|c|}
\hline Species & $2 n$ & Karyotype & FN & Origin & Reference \\
\hline M. cephalus & 48 & $48 \mathrm{a}$ & 48 & Western Italy & Cataudella et al. (1974) \\
\hline M. cephalus & 48 & $48 \mathrm{a}$ & 48 & South East India & Natarajan \& Subrahmanyam (1974) \\
\hline M. cephalus & 48 & $48 \mathrm{a}$ & 48 & Louisiana, USA & LeGrande \& Fitzsimons (1976) \\
\hline M. cephalus & 48 & $48 \mathrm{a}$ & 48 & South East Spain & Cano et al. (1982) \\
\hline M. cephalus & 48 & $48 \mathrm{a}$ & 48 & Texas, USA & Amemiya \& Gold (1986) \\
\hline M. corsula & 48 & $48 \mathrm{a}$ & 48 & - & Khuda-Bukhsh \& Manna (1974) \\
\hline M. curema & 28 & $20 m+4 s t+4 a$ & 48 & - & LeGrande \& Fitzsimons (1976) \\
\hline M. liza & 48 & $48 \mathrm{a}$ & 48 & - & Pauls \& Coutinho, (1990) (in Jordão et al. 1992) \\
\hline M. parsia & 48 & $48 \mathrm{a}$ & 48 & - & Chatterjee \& Majhi (1973) \\
\hline M. parsia & 48 & $48 \mathrm{a}$ & 48 & - & Khuda-Bukhsh \& Manna (1974) \\
\hline M. platanus & 48 & $48 \mathrm{a}$ & 48 & - & Jordão et al. (1992) \\
\hline
\end{tabular}

FN: fundamental number, i.e. number of chromosomal arms.

Table 2 Summary of cytogenetic observations on Mugil cephalus

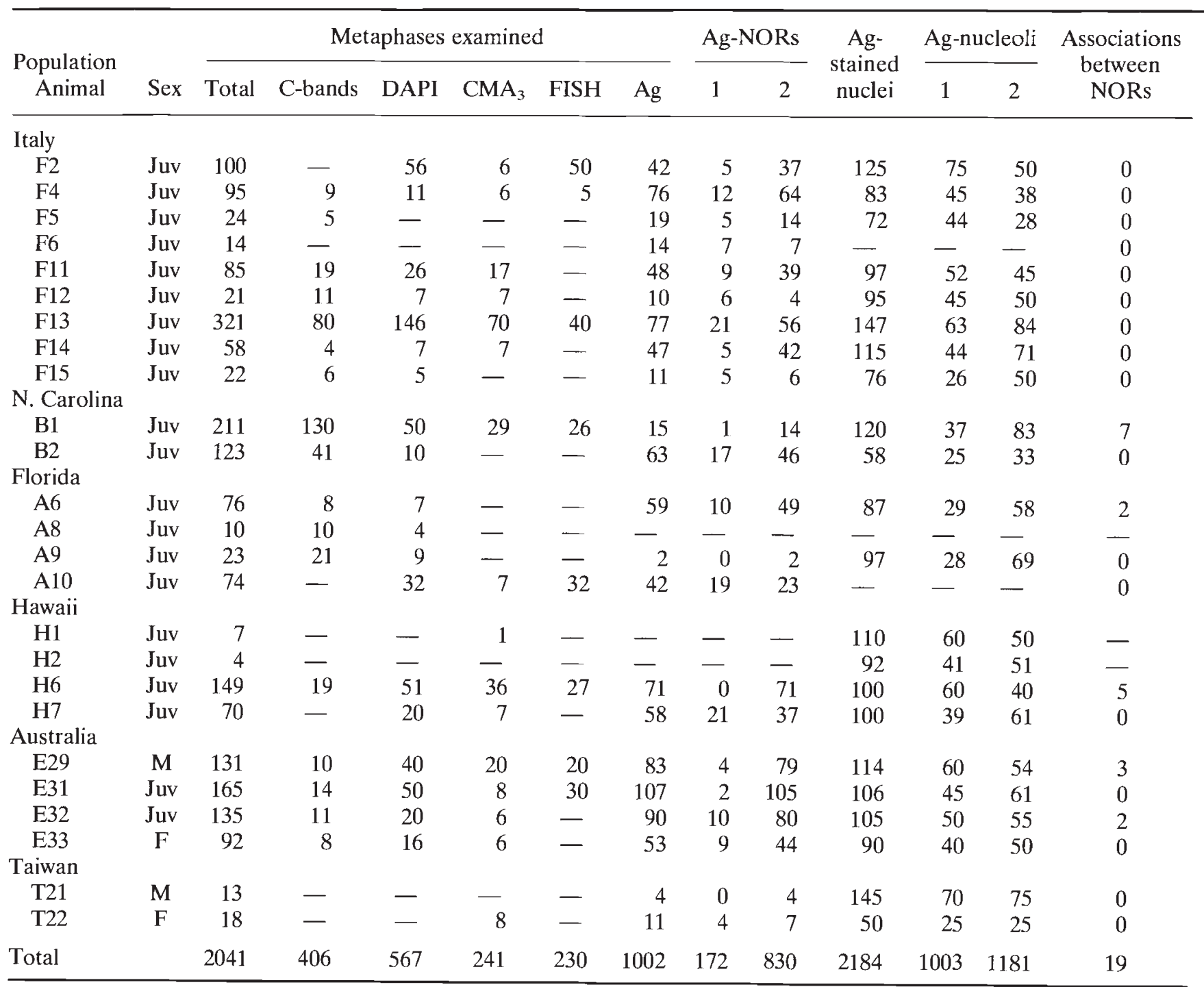


Sea), Southport and Mosquito Lagoon (respectively, B: North Carolina and A: Florida, U.S.A., West Atlantic Ocean), Oahu Island (H: Hawaii, Central Pacific Ocean), Brisbane (E: Australia, East Coast, South Pacific Ocean), Tainan (T: Taiwan, West Pacific Ocean). For eight specimens from four locales $(\mathrm{F}, \mathrm{B}, \mathrm{H}, \mathrm{T})$ preliminary cytogenetic observations have been reported (Crosetti et al., 1993). For the sake of data analysis, all the mullet specimens karyologically analysed are included in this report. Voucher specimens are deposited in the Museum of Comparative Anatomy, Rome University 'La Sapienza'.

Mitotic chromosomes were prepared from pooled cephalic kidney, spleen and gill cells using the standard air-drying procedure. NORs were identified by colloidal silver staining (Howell \& Black, 1980). Constitutive heterochromatin was detected by C-banding, as described by Sumner (1972). Fluorochrome staining with the GC-specific chromomycin $\mathrm{A}_{3}\left(\mathrm{CMA}_{3}\right)$ and the AT-specific DAPI was carried out as described by Sola et al. (1992b). FISH was performed using a $2 \mathrm{~kb}$ fragment of the human $18 \mathrm{~S}$ rDNA, labelled with biotin-7-dATP, following Lawrence et al. (1988) with modifications that will be published elsewhere. Some of the slides used for FISH were kept in the refrigerator for up to 4 years.

\section{Results}

More than 2000 metaphase plates from 25 specimens were analysed during this survey. Cytogenetic observations are summarized in Table 2. Specimens from all locales showed a karyotype composed of 48 acrocentric chromosomes uniformly decreasing in size. The different techniques produced a staining pattern common to specimens of both sexes from all populations. C-banding revealed constitutive heterochromatin at the centromeres of almost all chromosomes and at the terminal region of the long arm of chromosome 1 (Fig. 1a). On these chromosomes, Ag- (Fig. 1b) and $\mathrm{CMA}_{3}$-positive (Fig. 1c) signals are also present.

Thus, chromosome pair 1 is the only pair in the chromosome complement showing differentially stained regions, summarized in Fig. 2. The telomeric region of these chromosomes frequently appears heteropycnotic, i.e. faintly stained after Giemsa (Fig. 2a). The terminal C-bands (Fig. 2b) seem to involve a larger region than the merely heteropycnotic one whereas both $\mathrm{Ag}$ (Fig. 2c) and $\mathrm{CMA}_{3}$ (Fig. 2d) signals, i.e. NORs, correspond for size and location to the telomeric heteropycnotic region. As expected, because of the opposite base specificity compared to $\mathrm{CMA}_{3}$, DAPI-staining produces negative heteropycnosis in this region (Figs $2 \mathrm{e}$ and $3 \mathrm{a}$ ). All remaining chromosomes appear uniformly stained after DAPI (Fig. 3b).

The number of NORs in the complement was verified by counting the Ag-nucleoli in the nuclei (Table 2) and was never found to be higher than two. In eight specimens from five locales (F, B, A, $H, E)$, NOR number and localization were analysed by FISH (Figs $2 \mathrm{f}$ and $3 \mathrm{a}$ ) that confirmed the unique location of NORs on chromosome 1 . In some individuals, irrespective of their origin, heteromorphism in NOR size was detected, one NOR being almost twice its homologue in size, both after silver (Fig. 2c), $\mathrm{CMA}_{3}$-staining (Fig. 2d) and FISH (Fig. 2f).

\section{Discussion}

All populations shared the same chromosome complement and no changes were detected in

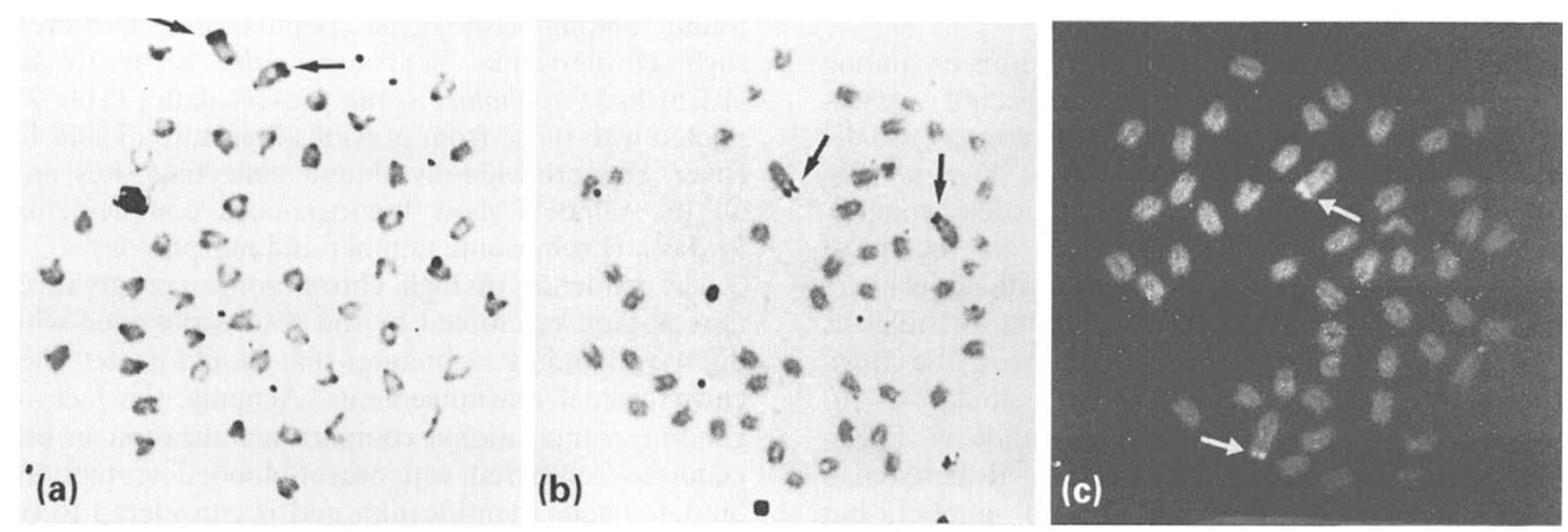

Fig. 1 Metaphase plates of Mugil cephalus after (a) C-banding, (b) Ag-staining and (c) $\mathrm{CMA}_{3}$-staining. Arrows indicate chromosome pair 1.

(c) The Genetical Society of Great Britain, Heredity, 76, 77-82. 

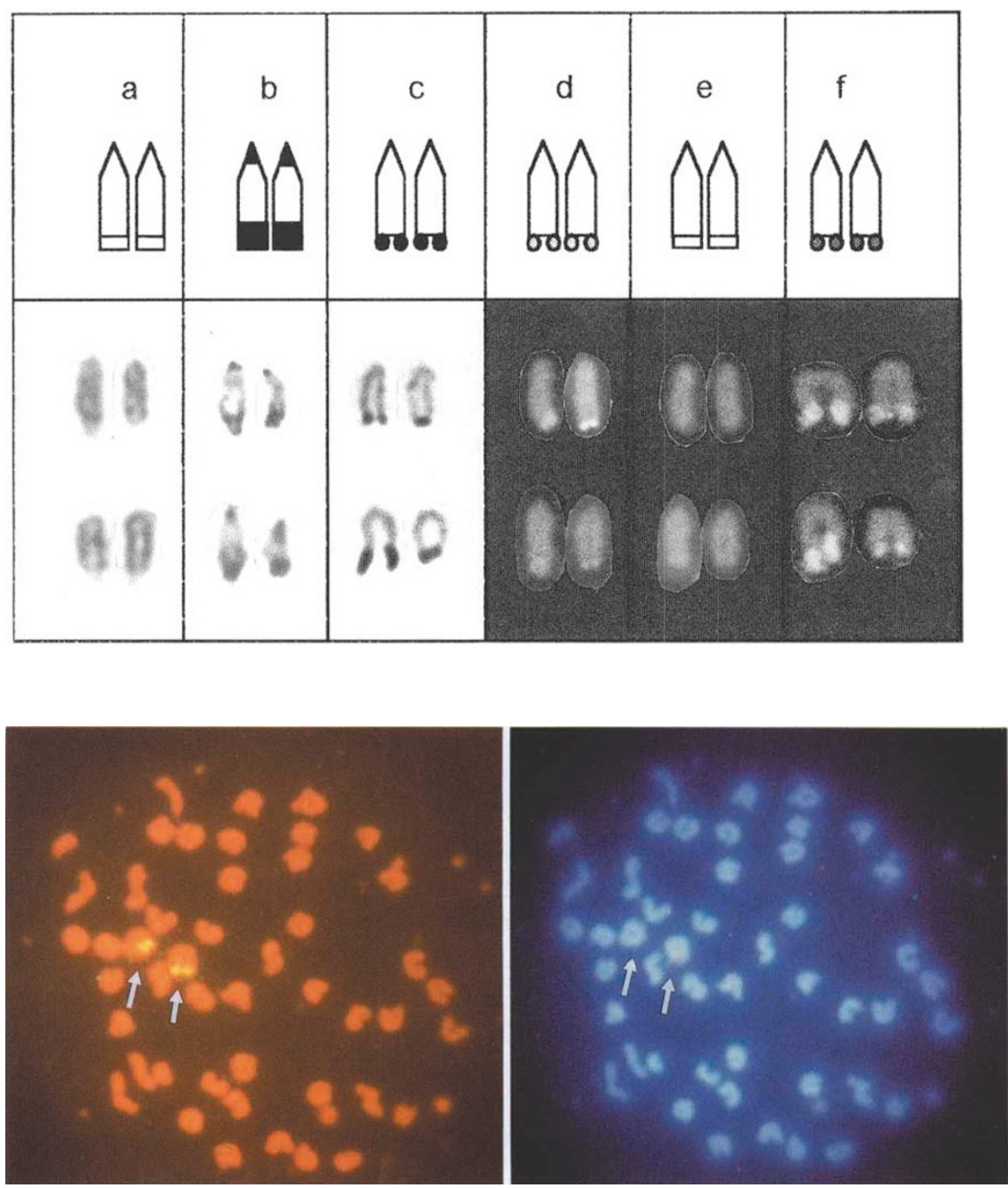

a

b
Fig. 2 Schematic representation and selected samples of chromosome pair 1 of Mugil cephalus after different staining techniques: (a) Giemsa; (b) C-banding; (c) Ag-staining; (d) $\mathrm{CMA}_{3}$-staining; (e) sequential DAPIstaining; (f) FISH.

Fig. 3 (a) FISH with ribosomal genes and (b) the same metaphases of Mugil cephalus counterstained with DAPI. Arrows indicate chromosome pair 1. heterochromatin and NORs. Therefore, neither population- nor sex-specific marker chromosomes were identified.

The absence of chromosomal differences among populations was not completely unexpected, according to the current opinion that karyology is usually best applied to detect differences at higher taxonomic levels. Moreover, the chromosome complement of $M$. cephalus corresponds to the most conservative one, i.e. the 48 all-acrocentrics proposed as the ancestral karyotype for teleosts (Ohno, 1974). However, whereas most of the Mugil species analysed show a karyotype similar to $M$. cephalus, that of $M$. curema (LeGrande \& Fitzsimons, 1976) was found to involve Robertsonian rearrangements, i.e. reduced diploid number, but conserved number of chromosomal arms (Table 1). This may indicate a structural propensity of the mullet karyotype to undergo fusions; chromosomal changes could therefore have occurred and could be found among conspecific populations. However, such chromosomal rearrangements seem to be absent in $M$. cephalus, as the present data (Table 2), pooled with those from previous literature (Table 1), cover 11 worldwide-distributed collecting sites and all the samples show homogeneous complements, for both chromosome number and morphology.

The evidence of high chromosome conservativeness is even reinforced by the results obtained with different banding techniques that should detect finer chromosomal rearrangements. Actually, the lack of genome compositional compartmentalization in fish genomes compared with warm-blooded vertebrates hinders bands identification and is considered to be a cause of chromosome stability and of low propensity for karyotypic changes (Bernardi, 1993). There- 
fore, had finer rearrangements occurred, their detection would have been quite difficult. Nevertheless, the techniques used in this survey allow investigation of heterochromatin and NORs, chromosomal regions often found to vary in fish.

No changes were observed in heterochromatin distribution, amount and composition. The centromeric heterochromatin is not related to a differential increase of AT- or GC-rich DNA as neither DAPI nor $\mathrm{CMA}_{3}$ on untreated slides produced enhanced fluorescence on centromeres (see Sola et al. (1992b) for details on fluorochrome staining after C-banding). Differential amounts of bases are only identifiable on the telomeric part of the C-bands on chromosomes 1 , corresponding to the location of NORs, that is $\mathrm{CMA}_{3}$-positive, i.e. GC-rich.

Such an association between GC-rich heterochromatin and ribosomal genes seems to be a feature of NORs quite common in teleosts, as originally proposed by Amemiya \& Gold (1986), although the nature of the association has to be clarified, i.e. whether rDNA is interspersed within the repeated sequences of the heterochromatin or constitutes these repeated sequences (Pendas et al., 1993a,b). However, in brown trout some minor $\mathrm{CMA}_{3}$-negative NORs have been localized by FISH (Pendas $e t$ al., 1993a). As far as the organization of ribosomal cistrons in $M$. cephalus is concerned, an overlapping between $\mathrm{Ag}, \mathrm{CMA}_{3}$ and FISH signals was observed; the $\mathrm{CMA}_{3}$-negative heterochromatin, proximally flanking the Ag-NORs, was also negative after FISH with the rDNA probe.

The Ag-NOR heteromorphism observed in different specimens was confirmed by both $\mathrm{CMA}_{3}$ staining and FISH, i.e. it has structural and not functional bases. Such heteromorphism supports the current opinion that the NOR-associated heterochromatin might be the cause of higher rates of rearrangements of these chromosome regions. On the other hand, all populations showed the same pattern of number of NORs and locations shared also by specimens from Texas (Amemiya \& Gold, 1986), and such homogeneity in specimens from locales so far apart is undoubtedly worth noting, considering that variability of NORs can be very conspicuous in some species of fish, as in salmonids (Phillips \& Hartley, 1988; Phillips et al., 1989; Pendas et al., 1993a) and in the genus Poecilia (Sola et al., 1992a,b; 1993).

Comparative data on constitutive heterochromatin in congeneric species are lacking except for those reported by Jordão et al. (1992) on $M$. platanus. In this species a pericentromeric location of heterochromatin was reported but no other $\mathrm{C}$-positive sites were described. This is quite surprising because $M$. cephalus and $M$. platanus share the same NOR locations on chromosome 1 . NORs data are available for only three other mugilid species, Liza aurata, $L$. ramada and Chelon labrosus (Delgado et al., 1991), that also show only one pair of NOR-bearing chromosomes; however, NORs are differently located, i.e. on the short arms of the smallest chromosome pair.

Both mtDNA (Crosetti et al., 1994) and geneenzyme (Rossi et al., 1995) analyses of the same and other populations of $M$. cephalus indicate an appreciable degree of genetic divergence and a possible lack of gene flow among at least some of them. Comparing the populations for which all sets of data are available, even the most genetically divergent populations, i.e. Hawaii and Taiwan, are karyologically uniform. Thus, the genetic differentiation is not supported by chromosome changes in M. cephalus. Nevertheless, this evidence is consistent with a general picture suggesting that chromosomal rearrangements have not played a major role in fish evolution.

\section{Acknowledgements}

We thank all those who permitted the collection of mullet samples around the world: G. F. Boots, NC, U.S.A.; C. S. Lee and C. S. Tamaru, Hawaii; R. Lenanton and C. Keenan, Australia; J. C. Kuo and the Hanaqua fish farm, Taiwan. The technical assistance of Mr L. Veroli is gratefully acknowledged. Collection of samples was financed by a grant from the National Geographic Society (no. 4167-89). This work was supported by research grants from CNR and MURST $40 \%$.

\section{References}

AMEMIYA, C. T. AND GOLD, J. R. 1986. Chromomycin $A_{3}$ stains nucleolus organizer regions of fish chromosomes. Copeia, 1986, 226-231.

AREFYEV, v. A. 1989. The application of the method of colchicine baths to studies of karyotypes of the young of two mullet species (Mugilidae) from the Black Sea. In: Dushkina, L. A. (ed.) Early Life History of Marine Species, pp. 139-149. Sb. Nauchn. Tr. VNIRO, Moscow.

BERNARDI, G. 1993. Genome organization and species formation in Vertebrates. J. Mol. Evol., 37, 331-337.

CANO, J., THODE, G. AND ALVAREZ, M. C. 1982. Karyoevolutive considerations in 29 Mediterranean teleost fishes. Vie Milieu, 32, 21-24.

Cataudella, s., Civitelli, M. v. AND CAPANNA, E. 1974. Chromosome complements of the Mediterranean 
mullets (Pisces, Perciformes). Caryologia, 27, 93-105. ChatterJeE, K. AND MAJHl, A. 1973. Chromosomes of Mugil parsia Hamilton (Teleostei, Mugiliformes: Mugilidae). Genen Phaenen, 16, 51-54.

CORTI, M. AND CROSETTI, D. 1995. Geographic variation in the grey mullet Mugil cephalus (Pisces, Mugilidae): a geometric morphometric analysis using partial warp scores. J. Fish Biol. (in press).

CROSETTI, D., AVISE, J. C., PlACIDI, F., ROSS1, A. R. AND SOLA, L. 1993. Geographic variability in the grey mullet Mugil cephalus: preliminary results of mtDNA and chromosome analyses. Aquaculture, 111, 95-101.

CROSETti, D., NELSON, w. S. AND AVISE, J. C. 1994. Pronounced genetic structure of mitochondrial DNA among populations of the circumglobally distributed grey mullet (Mugil cephalus). J. Fish Biol., 44, 47-58.

Delgado, J. v., THODE, G., LOBILLO, J., CAMACHO, M. E., Alonso, A. AND RODERO, A. 1991. Detección de la región del organizador nucleolar en cromosomas de la familia Mugilidae (Perciformes): precisiones técnicas. Arch. Zootec., 40, 301-305.

HOWELL, W. M. AND BLACK, D. A. 1980. Controlled silverstaining of nucleolus organizer regions with a protective colloidal developer: a 1-step method. Experientia, 36, 1014-1015.

JORDĀO, L. C., OlIVEIRA C., FORESTI, F. AND GODINHO H. M. 1992. Caracterização citogenética da tainha, Mugil platanus (Pisces, Mugilidae). B. Inst. Pesca, 19, 63-66.

KHUDA-BUKHSH, A. R. AND MANNA, G. K. 1974. Somatic chromosomes in seven species of teleostean fishes. Chrom. Inf. Sen., 17, 5-6.

LAWRENCE, J. B., VILLNAVE, C. A. AND SINGER, R. H. 1988. Sensitive, high-resolution chromatin and chromosome mapping in situ: presence and orientation of two closely integrated copies of EBV in a lymphoma line. Cell, $\mathbf{5 2}$, $51-61$.

LEGRANDE, w. H. AND FITZSIMONS, J. M. 1976. Karyology of the mullets Mugil curema and M. cephalus (Perciformes: Mugilidae) from Louisiana. Copeia, 1976, 388-391.

NATARAJAN, R. AND SUBRAHMANYAM, K. 1974. A karyotype study of some teleosts from Portonovo waters. Proc. Indian Acad. Sci., 79B, 173-196.

NAYYAR, R. P. 1966. Karyotype studies in thirteen species of fishes. Genetica, 37, 78-92.

oHNO, s. 1974. Protochordata, Cyclostomata and Pisces. In: John, B. (ed.) Animal Cytogenetics, vol. 4. Gebrüder Borntraeger, Berlin.

PAULS, E. AND COUTINHO, I. A. 1990. Levantamento citogenético em peixes de maior valor econômico do litoral
Fluminense, RJ (23 Lat/S). Congresso Brasileiro de Zoologia, 17, p. 325. Universidade Estadual de Londrina, 1990.

PENDÁs, A. M., MORÁN, P. AND GARCíA-VÁZQUez, E. 1993a. Multi-chromosomal location of ribosomal RNA genes and heterochromatin association in brown trout. Chromosome Res., 1, 63-67.

PENDÁS, A. M., MORÁN, P. AND GARCíA-VÁZQUEZ, E. 1993 b. Ribosomal RNA genes are interspersed throughout a heterochromatic chromosome arm in Atlantic salmon. Cytogenet. Cell Genet., 63, 128-130.

PHILlips, R. B. AND HARTLEY, S. E. 1988. Fluorescent banding patterns of the chromosomes of the genus Salmo. Genome, 30, 193-197.

PHILlips, R. B., PLEYTE, K. A. AND IHSSEN, P. E. 1989. Patterns of chromosomal nucleolar organizer region (NOR) variation in fishes of the genus Salvelinus. Copeia, 1989, 47-53.

RISHI, K. K. AND SINGH, J. 1982. Karyological studies on five estuarine fishes. Nucleus, 25, 178-180.

Rossi, A. R., CAPUla, M., CROSETTI, D., SOla, L. AND CAMPTON, D. E. 1995. Allozyme variation and genetic differentiation among global populations of striped mullet Mugil cephalus (Pisces: Mugilidae). Copeia (in press).

SOLA, L., 1ASElLI, V., ROSSI, A. R., RASCH, E. M. AND MONACO, P. J. 1992a. Cytogenetics of bisexual/unisexual species of Poecilia. III. The karyotype of Poecilia formosa, a gynogenetic species of hybrid origin. Cytogenet. Cell Genet., 60, 236-240.

SOLA, L., ROSSI, A. R., IASElli, V., RASCH, E. M. AND MONACO, P. J. 1992b. Cytogenetics of bisexual/unisexual species of Poecilia. II. Analysis of heterochromatin and nucleolar organizer regions in Poecilia mexicana mexicana by C-banding and DAPI, quinacrine, chromomycin $\mathrm{A}_{3}$, and silver staining. Cytogenet. Cell Genet., 60, 229-234.

SOLA, L., BRESSANELLO, S., RASCH, E. M. AND MONACO, P. J. 1993. Cytogenetics of bisexual/unisexual species of Poecilia. IV. Sex chromosomes, sex chromatin composition and Ag-NOR polymorphisms in Poecilia latipinna: a population from Mexico. Heredity, 70, 67-71.

SUMNER, A. T. 1972. A simple technique for demonstrating centromeric heterochromatin. Exp. Cell. Res., 75, 304-306.

THOMSON, J. M. 1963. Synopsis of biological data on the grey mullet (Mugil cephalus Linnaeus, 1758). Fisheries Synopsis 1, Division of Fisheries and Oceanography, CSIRO, Australia. 